\title{
Group-based intervention to improve socio- emotional health in vulnerable children
}

\begin{abstract}
Internalizing and externalizing problems present as difficulties in socio-emotional competence and predispose to a wide range of mental and physical health outcomes. This study examines the efficacy of an intervention (Pyramid Plus) in strengthening children's socio-emotional competencies. Participants (294 11year old children attending schools in Northern Ireland) were screened for socio-emotional difficulties using the Strengths and Difficulties Questionnaire (SDQ) and before being allocated to attend a Pyramid Club intervention $(\mathrm{n}=162)$, and a waiting list control $(\mathrm{n}=122)$. A $3 \times 2$ mixed-model design was used: group (intervention group vs. waiting list control) $\times 3$ time points (pre- vs. post-intervention vs. 12weeks follow up) to investigate the impact of the Pyramid Plus intervention. Teachers and children completed the SDQ-11-16years, and children completed the TEIQue-CSF ant all 3times. SDQ total difficult, internalizing and externalizing scores were reduced significantly, and prosocial and emotional intelligence scores were increased significantly compared to waiting list controls post intervention and at follow up. The Pyramid Plus intervention improves the socio-emotional health of vulnerable children through promoting positive outcomes as well as reducing socio- emotional deficits.
\end{abstract}

Volume I Issue 7 - 2014

\section{Tony Cassidy}

Ulster University, UK Correspondence: Tony Cassidy, Ulster University, Cromore
Road Coleraine Northern Ireland BT52 ISA, UK, Tel 4400000000000,Email t.cassidy@ulster.ac.uk

Received: November II, 2014 | Published: December 05, 2014

Keywords: internalizing, externalizing, emotional intelligence, intervention, socioemotional competence

Abbreviations: SDQ, strengths and difficulties questionnaire; TD, total difficulty; TEIQue-CSF, trait emotional intelligence questionnaire child short form; ANOVA, analysis of variance

\section{Introduction}

Behaviour problems among children represent a major public health and educational concern and are pivotal risk factors in developmental models of a wide range of adolescent difficulties. ${ }^{1}$ Problem behaviours at this stage are categorised under internalizing problems, which reflect a child's internal distress (e.g., depression, anxiety), and externalizing problems, which bring a child into conflict with others (e.g., rule breaking, aggression). Behavioural problems in childhood have been found to predict a range of difficulties in later life, including rejection by peers, failure in school, delinquency, job instability, substance abuse and problems in marital relationships. ${ }^{2-3}$ While these types of problem behaviours may be seen as potential expressions of mental health problems in childhood, there is no doubt that they are predictive of mental health problems in adolescence and young adulthood. ${ }^{4-6}$ Furthermore behaviour problems among children are also related to other problems including poor achievement at school, poor peer relations, and disrupted relationships with their parents. $^{7-9}$ While internalizing problems are associated with later depression and social adjustment, it seems that comorbidity or externalizing problems are more predictive of suicide ideation. ${ }^{10}$

There is an extensive research literature which has identified a range of risk factors for internalizing and externalizing problems including, childhood sexual abuse, ${ }^{11}$ parenting style, ${ }^{12-13}$ family relationships and adversity, ${ }^{1}$ bullying and victimisation ${ }^{14}$ socioeconomic disadvantage $\mathrm{e}^{15-16}$ and maternal education. Risk factors within the child are physical health problems, difficult temperament, and insecureattachment-related behaviours while risk factors in families are parent mental health problems (particularly depression), separation/ divorce, daily hassles, and a controlling parenting style. ${ }^{17}$ Risks factors more specific to externalizing problems are male gender, having siblings, young and low-educated parents, marital problems, poor social support, low parenting efficacy, harsh discipline, and use of poorquality childcare services, and factors more specific to internalizing problems include temperamental inhibition, parent illness/death, parental anxiety, and overprotective parenting that models avoidant coping to children. ${ }^{17}$

More recently there is a growing literature focusing on factors which protect children from internalizing and externalizing problems. ${ }^{18}$ These latter include individual factors such as, being female, ${ }^{19-20}$ having a positive .temperament, ${ }^{21}$ sociability, ${ }^{22-23}$ effective emotional regulation or emotional intelligence ${ }^{22,24-25}$ having higher general intelligence, ${ }^{26}$ effective problem-solving and coping skills, ${ }^{23,27-29}$ internal locus of control, ${ }^{30-31}$ optimism ${ }^{28,32}$ self determination ${ }^{28,33}$ sense of humour ${ }^{34-35}$ self-efficacy, ${ }^{36}$ and having a positive attitude towards school. ${ }^{37}$

Evidence suggests that internalizing and externalizing problems can co-occur and have similar aetiologies ${ }^{15}$ although it is likely that there are at least 3 categories, pure externalizing, pure internalizing, and co-varying externalizing plus internalizing. ${ }^{38}$ In school settings externalizing problems cannot go unnoticed but the same cannot be said for internalizing problems which often manifest as shyness or sensitivity. Teachers tend not to be very good at identifying internalizing problems and receive no real training in the area. ${ }^{39}$ Shyness-sensitivity plays an important role in social and psychological adjustment in childhood and adolescence..$^{40}$ Children who display shy and sensitive behaviour are likely to experience difficulties in peer interactions and relationships ${ }^{1,41-42}$ and may develop negative selfperceptions and other psychological problems such as loneliness and depression. ${ }^{41}$ The difficulties that shy-sensitive children experience may be related to the emphasis on assertiveness, competitiveness, and self-expression in the society. ${ }^{43-44}$ and longitudinal research has shown that internalizing problems in childhood predict poorer educational attainment, career stability, and mental health. ${ }^{20}$ The importance of the school's role in the promotion of emotional health and well- 
being has grown while the time and resources allotted to this have dwindled. ${ }^{45}$ These changes have resulted in a steady increase in the prevalence of multi-agency delivery of school-based emotional health and well-being programmes. ${ }^{46-49}$ In a recent meta-analysis, Durlak et al. ${ }^{50}$ reported that $59 \%$ of schools in the United States offer programmes that support socio-emotional development and that policy makers, teachers, and other agencies can make a positive impact on the socio-emotional development of children through the inclusion of such evidence-based programmes in the curriculum. Importantly, evaluations of this type of programme have shown that teachers, school support staff, and community members can be trained to deliver programmes as effectively as clinicians. ${ }^{49,51-52}$ A further advantage of these changes is that they have shifted the focus away from strategies based upon the treatment of mental health 'problems' towards a more preventive approach encapsulated by 'the recent growth in interest in positive psychology ${ }^{45,53}$ aimed at promoting the acquisition of health, well-being, and socio-emotional competencies. Socio-emotional competence has been described as 'effectiveness in interaction'. Goleman ${ }^{54}$ outlines some of the socio-emotional competencies it is desirable for children to develop, including selfknowledge, emotional regulation, social skills, and empathy. This suggests a degree of organization and control whereby children self-regulate their behaviour to effectively initiate and maintain peer interactions, taking both their personal needs and those of their social group into consideration. ${ }^{55}$ Additionally, prosocial peer nominations for both boys and girls were rated higher where the target children showed greater socio-emotional competency as measured by emotional regulatory control ${ }^{56}$ and trait emotional intelligence ${ }^{57}$ a construct which 'concerns emotion- related dispositions and self-perceptions'. ${ }^{58}$ Peers represent an important influence in the successful development of social skills for both children who display externalizing behavioural difficulties (e.g., aggression) and children who internalize (e.g., social withdrawal). ${ }^{59}$ Typically, the majority of children in middle childhood will make a smooth transition between the socializing influences of their parents and siblings ${ }^{60}$ to those of an accepting peer and friendship group and will adapt with relative ease to the academic and social challenges of the school environment. ${ }^{61-62}$ However, those who have low trait emotional intelligence ${ }^{57,63}$ poor emotional regulatory control, ${ }^{56}$ higher levels of emotional negativity, ${ }^{64}$ or low peer status ${ }^{65}$ are at risk of failing to develop the necessary levels of socio-emotional competence to similarly thrive in school life. Particularly vulnerable are those children perceived by others to exhibit signs of social withdrawal and who find it hard to participate either because they are behaviourally inhibited or excluded by their peers. Such children are also at risk of future development of depression and other internalized disorder ${ }^{18}$ and it has been shown that teachers are less likely to recognize that they have a problem than children with externalizing disorders. ${ }^{66}$ The three-stage Pyramid model ${ }^{67}$ provides a school-based intervention aimed at improving the socio-emotional skills of children who present as withdrawn, socially isolated, and emotionally vulnerable. ${ }^{68}$ Previous research into the efficacy of the Pyramid intervention with UK primary school Year 3 children ${ }^{67}$ showed an overall reduction in Pyramid attendee children's Strengths and Difficulties Questionnaire (SDQ) Total Difficulty (TD) scores ${ }^{69}$ More recent studies showed that the intervention reduced emotional and peer problems and increased prosocial behaviour in vulnerable children. ${ }^{70-71}$ The Current Study.

The Pyramid ethos is based upon strengthening friendship skills, building emotional resilience, and social skills, ${ }^{68,72}$ these aims clearly map onto three of the domains of the SDQ (Emotional symptoms, Peer problems, and Prosocial behaviour), and on to emotional intelligence.
An advantage of the SDQ over other child behaviour measures is that it includes positive items and a prosocial behaviour scale that is considered purely as'strength'. The Pyramid intervention also seeks to build strength rather than just focus upon reducing deficits, ${ }^{68,72}$ and in this study we added the Trait Emotional Intelligence Scale - child version (TEIque $\mathrm{CF}$ short form). ${ }^{58,63} \mathrm{~A}$ principal aim of the current study was to investigate the impact of the Pyramid intervention on children's scores in the individual SDQ domains and on emotional intelligence. Second, it sought to further previous research ${ }^{67}$ into the impact of the Pyramid Plus intervention on the socio-emotional wellbeing of the Pyramid attendee children by including a 12 week follow up stage. Consistent with previous findings, ${ }^{73}$ it was predicted that while the baseline SDQ and TEIque scores of the Pyramid attendee children would be similar to a waiting list control group, postintervention their scores would have reduced significantly below the waiting list control group, and that these scores would be maintained at follow up.

\section{Method}

\section{Design}

A mixed-model design was used; group (intervention group vs. waiting list control) $\times 3$ time points (pre- vs. 10 week post-intervention vs. 12 week follow up) with repeated measures on the time factor. Implementation fidelity was monitored by ongoing supervision provided by the Pyramid Co-ordinator who visited each Club at least twice during the 10 -week period to ensure that Leaders were running the Clubs in adherence with the Pyramid intervention manual. All coordinators received standard training based on the Pyramid manual.

\section{Participants}

All the participants were NI primary school pupils in Year 7 (age 11) attending 13 participating schools. All children were in their 11th year at the start of data collection and there were a total of 294 (122 boys and 172 girls). Of these 162 (100 girls and 62 boys) took part in clubs. In addition 132 (72 girls and 60 boys) were identified as suitable for clubs but due to limited resources were unable to receive clubs during the data collection period and were therefore treated as waiting list controls.

\section{Comparison groups}

Data were collected in the schools over the course of two academic years. A non-equivalent groups design was used, as the Pyramid intervention is a selective one and a randomized method of allocating children to either treatment or control group was unsuitable. Similarly the use of a 'waiting list' control group, wherein children who are waiting for intervention serve as controls to those who are already receiving intervention ${ }^{74}$, was also considered unsuitable from an ethical perspective. However due to limited funding there were insufficient places available to include all children assessed as having need to attend, hence a waiting list control group was unavoidably presented. The structure of the intervention is shown in (Table 1).

\section{Selection Process for Pyramid Participants}

The Pyramid Intervention is both a targeted and indicated intervention programme. Children were selected for Pyramid Plus based both on their SDQ scores and or on the basis of the involved professional's knowledge of the risk factors for internalisation problems that may have been ongoing in their lives. This method was adopted in line with the selection procedures recommended in the Pyramid intervention manual. ${ }^{68}$ Children who scored above the 
threshold on the Emotional Symptoms and or Peer Problems and or below the threshold on Pro-social Skills who were not displaying comorbid externalizing problems were offered a place in the club.

\section{The intervention}

The Pyramid Club intervention is a therapeutic school-based intervention that is implemented as a Club during the school day over ten weekly sessions of 90 min (Figure 1) and. ${ }^{67}$

Pyramid is a manualized selective intervention that seeks to improve children's socio- emotional competence. It is aimed at children who are quiet, shy, and behaviourally more likely to internalize, and those who appear to find peer and adult interaction difficult. ${ }^{68,72}$

The Pyramid Year 3 intervention comprises a three-stage model.

\section{Stage One}

Screening of the whole year group by the class teacher to assess socio- emotional health status using the SDQ. ${ }^{75}$

Table I Note : ${ }^{* * *} \mathrm{p}<.001 ;{ }^{* *} \mathrm{p}<.01 ;{ }^{*} \mathrm{p}<.05$

\begin{tabular}{|c|c|c|c|c|c|c|}
\hline \multirow[t]{2}{*}{ SDQ Subscale } & UK Norm & UK Norm & NI Sample & NI Sample & $\mathbf{t}$ & $\mathbf{t}$ \\
\hline & Teacher & Self-report & Teacher & Self-report & Teacher & Self-report \\
\hline & $(\mathrm{N}=3407)$ & $(\mathrm{N}=4228)$ & $(\mathrm{N}=294)$ & $(\mathrm{N}=294)$ & & \\
\hline Emotional & $1.3(1.9)$ & $2.8(2.1)$ & $3.6(2.3)$ & $3.8(2.2)$ & $16.5^{* * * *}$ & $7.6 * * *$ \\
\hline Conduct & $0.9(1.7)$ & $2.2(1.7)$ & $2.0(1.4)$ & $2.2(1.4)$ & $13.4^{* * *}$ & ns \\
\hline Hyperactivity & $2.6(2.7)$ & $3.8(2.2)$ & $3.0(2.2)$ & $2.9(1.9)$ & $2.9 * *$ & $-7.9 * * *$ \\
\hline Peer & $\mathrm{I} .4(\mathrm{I} .8)$ & I.5(I.4) & $2.5(1.8)$ & $2.7(1.6)$ & $9.9 * * *$ & $11.6 * * *$ \\
\hline \multirow[t]{4}{*}{ Pro-social } & $7.1(2.4)$ & $8.0(1.7)$ & $7.0(1.7)$ & $7.3(1.3)$ & ns & $-8.6 * * *$ \\
\hline & Females & Females & NI Sample & NI Sample & $\mathbf{t}$ & $\mathbf{t}$ \\
\hline & Teacher & Self-report & Teacher & Self-report & Teacher & Self-report \\
\hline & $(\mathrm{N}=4073)$ & $(N=2135)$ & $(\mathrm{N}=\mid 72)$ & $(\mathrm{N}=172)$ & & \\
\hline Emotional & I.4(I.9) & $2.6(1.9)$ & $3.6(2.2)$ & $3.6(2.2)$ & $10.8 * * *$ & $4.8 * * *$ \\
\hline Conduct & I.2(I.8) & $2.4(1.7)$ & $2.3(1.6)$ & $2.2(1.4)$ & $7.6 * * *$ & ns \\
\hline Hyperactivity & $3.7(3.0)$ & $3.9(2.2)$ & $3.2(1.9)$ & $2.6(1.6)$ & $-2.7 * *$ & $-8.7 * * *$ \\
\hline Peer & I.5(I.9) & I.6(I.4) & $2.6(1.8)$ & $2.5(1.6)$ & $6.5 * * *$ & $6.3 * * *$ \\
\hline \multirow[t]{4}{*}{ Pro-social } & $6.6(2.5)$ & 7.5(I.7) & $6.6(1.8)$ & $7.3(1.3)$ & ns & Ns \\
\hline & Males & Males & NI Sample & NI Sample & $\mathbf{t}$ & $\mathbf{t}$ \\
\hline & Teacher & Self-report & Teacher & Self-report & Teacher & Self-report \\
\hline & $(\mathrm{N}=4 \mid 35)$ & $(N=2093)$ & $(\mathrm{N}=122)$ & $(\mathrm{N}=122)$ & & \\
\hline Emotional & I.4(I.9) & $3.0(2.1)$ & $3.5(2.3)$ & $3.9(2.1)$ & $11.6 * * *$ & $5.6 * * *$ \\
\hline Conduct & $0.6(1.3)$ & $2.0(1.6)$ & $1.8(1.2)$ & $2.2(1.4)$ & $12.7 * * *$ & ns \\
\hline Hyperactivity & $2.1(2.3)$ & $3.6(2.2)$ & $2.8(2.4)$ & $3 . I(2.0)$ & $3.7^{* * *}$ & $-2.9 * *$ \\
\hline Peer & I.2(1.6) & I.4(I.4) & $2.4(1.8)$ & $2.8(1.7)$ & $8.4 * * *$ & $10.0 * * *$ \\
\hline Pro-social & $7.9(2.1)$ & $8.5(1.4)$ & $7.2(1.6)$ & $7.3(1.4)$ & $-5.5 * * *$ & $-1 \mathrm{I} . \mathrm{I} * * *$ \\
\hline
\end{tabular}

Table 2 Means and standard deviations for SDQ and TElque Data by study group

\begin{tabular}{|c|c|c|c|c|c|c|}
\hline \multicolumn{7}{|c|}{ Pyramid Group Who Received Intervention } \\
\hline \multicolumn{4}{|c|}{ Teacher rating data } & \multicolumn{3}{|c|}{ Self Report Data } \\
\hline & TI & T2 & T3 & TI & T2 & T3 \\
\hline & Mean (Sd) & Mean (Sd) & Mean (Sd) & Mean (Sd) & Mean (Sd) & Mean (Sd) \\
\hline Emotional & $3.9(2.4)$ & $2.7(1.6)$ & $2.7(1.0)$ & $4.2(2.3)$ & $2.6(1.4)$ & $2.9(I . I)$ \\
\hline Conduct & $2.1(1.5)$ & $1.7(1.0)$ & $1.7(0.7)$ & $2.4(1.6)$ & $1.6(0.9)$ & $1.8(1.2)$ \\
\hline Hyperactivity & $3.4(2.6)$ & $2.2(1.5)$ & $2.4(1.2)$ & $3.0(2.1)$ & $2.5(1.7)$ & $2.6(2.3)$ \\
\hline Peer & $2.6(1.9)$ & $\mathrm{I} .8(0.7)$ & $1.7(0.6)$ & $2.9(1.7)$ & $1.9(1.1)$ & $1.5(0.7)$ \\
\hline Pro-social & $6.7(1.5)$ & $8.5(1.5)$ & $8.5(1.0)$ & 7.I(I.3) & $8.4(1.4)$ & $8.6(1.4)$ \\
\hline Total difficulties & II.9(5.2) & $8.6(3.2)$ & $8.6(2.3)$ & $12.5(5.4)$ & $8.4(3.3)$ & $8.8(3.5)$ \\
\hline Internalizing & $6.6(3.2)$ & $4.5(1.8)$ & $4.5(I .3)$ & $7.2(3.4)$ & $4.5(1.9)$ & $4.5(1.4)$ \\
\hline Externalizing & $5.4(3.5)$ & $3.9(2.1)$ & 4.I(I.6) & $5.4(3.1)$ & 4.I(I.9) & $4.3(3.2)$ \\
\hline Emotional IQ & & & & $2.8(0.5)$ & $3.7(0.5)$ & $3.6(0.5)$ \\
\hline \multicolumn{7}{|c|}{ Waiting List Control Group } \\
\hline & TI & T2 & T3 & TI & T2 & T3 \\
\hline & Mean (Sd) & Mean (Sd) & Mean (Sd) & Mean (Sd) & Mean (Sd) & Mean (Sd) \\
\hline Emotional & $3.6(1.9)$ & $3.4(1.5)$ & $3.6(1.0)$ & $3.4(2.1)$ & $3.5(1.5)$ & $3.9(1.8)$ \\
\hline Conduct & $2.2(1.4)$ & $2 . I(I .2)$ & $2.2(0.9)$ & $2.3(I .2)$ & $2.2(1.8)$ & $2.2(1.5)$ \\
\hline Hyperactivity & $3 . I(0.9)$ & $2.7(1.0)$ & $3 . I(0.8)$ & $3.1(1.4)$ & $3 . I(0.9)$ & $3.3(1.7)$ \\
\hline Peer & $2.9(2.0)$ & $3.0(1.1)$ & $3 . I(0.9)$ & $2.8(1.6)$ & $3.2(1.2)$ & $3 . I(2.0)$ \\
\hline Pro-social & $6.4(2.1)$ & $7.8(1.2)$ & $7.7(0.9)$ & $7 . I(1.4)$ & $7.5(1.7)$ & $7.6(1.6)$ \\
\hline Total difficulties & $11.9(3.7)$ & $11.2(3.2)$ & $12.5(5.0)$ & II.5(4.I) & $12.1(3.3)$ & $11.9(2.7)$ \\
\hline Internalizing & $6.5(3.1)$ & $6.4(2.0)$ & $6.7(1.7)$ & $6.2(3.0)$ & $6.8(2.1)$ & $6.9(3.5)$ \\
\hline Externalizing & $5.3(1.7)$ & $4.8(1.7)$ & $5.2(1.4)$ & $5.4(2.1)$ & $5.3(1.7)$ & $5.5(2.6)$ \\
\hline Emotional IQ & & & & $2.8(0.6)$ & $2.7(0.6)$ & $2.8(0.8)$ \\
\hline
\end{tabular}


Table 3 Main effects and interactions from Mixed Anova.All main effects were between TI v T2 \& TI v T3*p<.05**p<.0I***p<.00I

\begin{tabular}{|c|c|c|c|c|c|c|c|c|}
\hline \multicolumn{5}{|c|}{ Teacher-Rating Data } & \multicolumn{4}{|c|}{ Self-Report Data } \\
\hline Variables & Main effects & n2 & Interactions & $\mathbf{n 2}$ & Main effects & n2 & Interactions Intervention effects & $\mathbf{n 2}$ \\
\hline & & & \multicolumn{6}{|c|}{ Intervention effects } \\
\hline & F-value & & F-value & & F-value & & F-value & \\
\hline Emotional & $8.80 * *$ & 0.03 & $7.74 * * *$ & 0.26 & $6.4 I * *$ & 0.02 & $10.45 * * *$ & 0.27 \\
\hline Conduct & ns & & ns & & ns & & $3.74 * *$ & 0.03 \\
\hline Hyperactivity & ns & & $8.18 * * *$ & 0.06 & ns & & ns & \\
\hline Peer & $3.66 *$ & 0.01 & $6.49 * * *$ & 0.15 & $4.65 * *$ & 0.02 & $14.33 * * *$ & 0.17 \\
\hline Pro-social & $58.06 * * *$ & 0.08 & $16.77 * * *$ & 0.21 & $16.6 \mid * * *$ & 0.06 & $6.04 * * *$ & 0.24 \\
\hline Total difficulty & $10.53 * * *$ & 0.04 & $14.26 * * *$ & 0.1 & $28.09 * * *$ & 0.02 & $28.17 * * *$ & 0.09 \\
\hline Internalizing & $10.35 * * *$ & 0.04 & II.79*** & 0.28 & $6.38 * *$ & 0.02 & I7.7|*** & 0.22 \\
\hline Externalizing & $3.36^{*}$ & 0.01 & $6.93 * * *$ & 0.05 & ns & & $2.72^{*}$ & 0.02 \\
\hline Emotional IQ & & & & & $37.4 I^{* * *}$ & 0.12 & $54.01 * * *$ & 0.28 \\
\hline
\end{tabular}

\section{Stage Two}

A multi-agency meeting takes place attended by the Special Educational Needs Co-ordinator, the year-group teachers, the local Pyramid Co-ordinator and any other agencies involved in care of the children. At this meeting, the SDQ scores are reviewed in relation to the SDQ banding criteria (http://www.sdqinfocom/ScoreSheets/ e2.pdf) and this information is then used to allocate children to the Pyramid intervention with onward referral of other children to appropriate agencies where necessary.

\section{Stage Three}

After-school Pyramid Clubs are delivered for the selected children.

\section{Measures}

The Strengths and Difficulties Questionnaire (SDQ): ${ }^{75}$ The SDQ was used to measure the socio-emotional status of the participants, pre- intervention, post-intervention, and at 12 weeks post-intervention follow-up. The SDQ is a brief behavioural screening questionnaire that takes a few minutes to complete by parents, carers, or in this case, teachers of children aged 4-11years. There is also a self-report version for 11-15year olds and as children were in their 11 th year both versions were used. It is widely used internationally and in the UK National Health Service and UK schools. It comprises 25 items divided into five sub- scales; four of which measure potential 'difficulties' being emotional symptoms, conduct problems, hyperactivity, and peer relationship problems. The fifth sub-scale measures prosocial behaviour and is treated as a 'strength'. Each sub-scale score can range from 0 to 10 . A higher score indicates more problems/symptoms except for the prosocial behaviour sub-scale where a lower score indicates more problems. A total difficulties (TD) score is calculated by summing the four negative sub-scale scores. The measure can be used to define 'caseness' using combinations of the four negative subscale scores. The informant-rated version of the SDQ has been shown to function, in terms of reliability, validity, and sensitivity, as well as the long-established Rutter questionnaires.

The Trait Emotional Intelligence Questionnaire Child Short Form (TEIQue-CSF). The TEIQue-CF measures 9 of the 15 adult facets and has been shown to display acceptable levels of internal consistency ${ }^{63,73}$ in two separate samples and also displayed temporal stability $(r=.79)$ similar to that found in adult samples. It has a self-rating and teacher rating version suitable for use in children as young as eight years old.

\section{Ethical approval}

Ethical approval for the study was granted by the University's Ethics Committee.

\section{Results}

The data from the current study was compared to UK means for the SDQ dimensions using one-sample t-tests as shown in (Table 1). Comparing teacher-rated data shows the NI children scoring significantly higher than UK norms on emotional problems, conduct problems, hyperactivity, and peer problems but not differing significantly on the pro-social dimension. On the self-report data NI child score significantly higher on emotional and peer problems, significantly lower on hyperactivity and the pro-social dimension but do not differ significantly on conduct problems. When comparisons are made separately for males and females some interesting differences emerge. NI girls score significantly higher on teacher-rated emotional problems, conduct problems, and peer problems, significantly lower on teacher-rated hyperactivity, significantly higher on self-reported emotional and peer problems, significantly lower on hyperactivity, and do not differ on self-reported conduct problems, or on either teacher-rated or self-reported pro-social behaviour from the norms. NI boys score significantly higher on teacher-rated emotional, conduct, hyperactivity, and peer problems, significantly lower on teacher-rated pro-social behaviour, significantly higher on self-reported emotional and peer problems, significantly lower on self-reported hyperactivity and pro-social behaviour, and do not differ on conduct problems from the norms. The most noticeable and perhaps unsurprising difference is that boys score below, and girls do not differ from the norm on pro-social behaviour. In addition girls score lower than the norm on hyperactivity on both teacher and self-report measures, whereas while teachers rate boys above the norm the boys rate themselves below the norm on hyperactivity.

The main analysis involved a two-way mixed-model analysis of variance (ANOVA) with group (Pyramid intervention and waiting list control) as the between-subjects variable and repeated measures (within-subjects) on the time factor (baseline to post-intervention to follow-up). Mauchly's test of Sphericity was significant for all variables so we used the Greenhouse-Geisser correction in interpreting the significance of main and interaction effects from the mixed Anova analysis. The descriptive statistics for this analysis are shown in (Table 2) and the main effects, interaction effects and effect sizes are shown in (Table 3).

Main effects reflect overall changes in scores across the 3 time periods, while the interaction effects show the impact of the intervention. Because of the larger numbers in the intervention group there were sufficient changes in means scores across the total sample to show up as main effects. However the interactions and post hoc comparisons show that these effects were only for the intervention group, and that the significant differences were between time 1 
(baseline) scores and both time 2 (end of treatment) and time 3 (follow up) scores. The intervention produced a significant reduction in total difficulties and a significant increase in prosocial values both for the self-rated and teacher-rated scores and this change in scores were maintained through to the 12 week follow up. Looking at the dimensions that make up the total difficulties scores it appears that this effect was mainly on emotional difficulties and peer difficulties with scores on both these dimension reduced significantly for both self-rated and teacher-rated scores. These are the dimensions that reflect internalizing problems and the effect was carried through when internalizing scores were analysed. Again there were interactions on internalizing for both self and teacher ratings. There was only an effect on conduct problems for self ratings, and only an interaction effect on hyperactivity for teacher ratings. These are the dimensions contributing to externalizing problems and there was an interaction effect for externalizing problems for both teacher and self-ratings. However when we look at the partial eta squared vales (n2 $=.05$ and .02 ) this was a small effect indicating that the intervention had a bigger impact on internalizing and prosocial scores. In fact the intervention effect size was large for both teacher ratings and self-ratings on, emotional ( $\mathrm{n} 2=.26$ and $\mathrm{n} 2=.27$ ), peer problems ( $\mathrm{n} 2=.15$ and $\mathrm{n} 2$ $=.17$ ), pro-social behaviour ( $\mathrm{n} 2=.21$ and $\mathrm{n} 2=.24$ ), and internalizing problems ( $\mathrm{n} 2=.28$ and $\mathrm{n} 2=.22)$. In addition the intervention had a significant impact on emotional intelligence with scores increasing from baseline to time 2 and maintaining through to follow up, with an effect size (n2=.28).

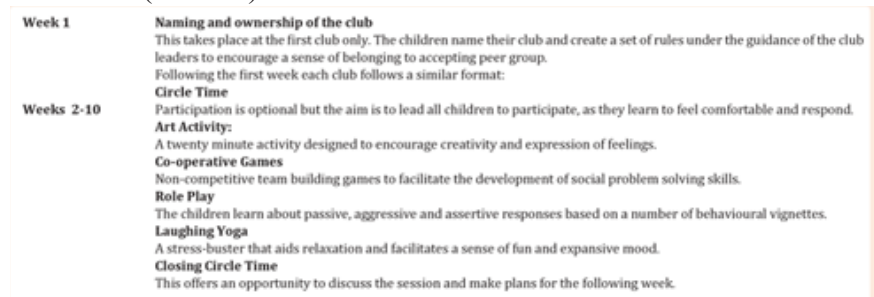

Figure I Modified Model. Modelling High Risk Sexual Behavior in HIVNegative Gay Men 6.

\section{Discussion}

The aim of this study was to evaluate the impact of the Pyramid Plus intervention on SDQ scores and emotional intelligence for these eleven year old children. The results show that the intervention had a significant impact and that this impact was maintained through to follow up. The largest impact was on internalizing problems, prosocial behaviour and emotional intelligence with children in the intervention group showing significant improvements compared to the waiting list controls and ending up with scores which were comparable to the group who did not seem to need the intervention. While the effect was not quite so large the intervention did significantly reduce externalizing scores and total difficulty scores. The impact of Pyramid on both internalizing and externalizing scores is evidence of the breadth of impact in these separate areas of risk behaviour. However in addition to pure externalizing and pure internalizing problems there is a third comorbidity category, ${ }^{38}$ which may pose even greater risk. ${ }^{10}$ The finding that the intervention reduces total difficulty scores suggests that it impacts on the comorbidity aspect as well. In addition, while there were differences in teacher ratings compared to self ratings both identified very similar levels of change. This extends and supports previous work with Pyramid Plus. ${ }^{70}$

The Pyramid model focuses on peer relations and the emotional regulation aspects of the SDQ and on emotional intelligence, essentially on internalizing problems. These are the problems most likely to go undetected in children and even if detected may go unreported or untreated. ${ }^{39}$ Externalizing behaviour is much easier to detect and more likely to attract interventions (Liu 2004), and there are substantially more interventions available. ${ }^{76}$ For example parenting interventions work well in preventing externalizing problems. ${ }^{77}$ In their substantial systematic review ${ }^{76}$ identify a paucity of interventions for internalizing problems, "we believe that further research is urgently needed on early prevention for emotional problems, because there is a paucity of effective programmes". The current study meets that need. It may very well be that the lack of success in some interventions may reflect their failure to encompass emotional or internalizing problems which may underpin many behavioural issues.

Apart from the more serious mental health issues, a considerable body of research has shown that the success of social functioning in middle childhood is related to the ability to self-regulate emotion. ${ }^{47,56}$ Additionally, children who are shown to have strong emotional regulatory control are more likely to receive favourable peer ratings and be viewed as socially competent by their teacher. ${ }^{20}$ Thus, the improvements made in the Pyramid group emotional symptoms scores demonstrate that post-intervention these children had acquired a greater level of emotional control suggesting that this would facilitate their ability to effectively initiate and maintain interaction with both peers and adults ${ }^{17}$ competencies necessary to ensure they flourish at school. Furthermore, support for the notion that Pyramid children were interacting more successfully with their peers post-intervention is provided by the similar trend of improvements in their prosocial and emotional intelligence scores.

There are probably three main limitations of the current study, i.e. the short term follow up, the fact that participants were not randomly allocated, and the limited measures used, which in reverse indicate potential future directions. While a 12 week follow up showing the maintained effect is substantial it would be desirable to see if the effect is maintained, in particular through the transition to the next level of education. Ideally a fully randomised control trial would provide more robust results, though one might query if such a design is ever possible. It is certainly both practically and ethically difficult to achieve in the real world. The current design, albeit through happenstance, provides quite an effect test of the intervention though more equal numbers across conditions would have improved it and would be desirable in future studies. Finally a wider range of outcome measures would have enabled a more detailed analysis of impact on variables such as resilience, self-efficacy and peer relations. However the lives of children across the world should not be held ransom to the pedantic desires of scientists. This intervention works for many children and in the philosophy of Hippocrates at least it does no harm.

Clearly internalizing and externalizing problems are risk factors for later mental health problems and the fact that they are amenable to change through a school-based intervention such as Pyramid Plus suggests an urgent need for governments to establish such programmes as part of the curriculum. Even earlier intervention is required and indeed Pyramid does work for younger children as well. ${ }^{78}$

\section{Conclusion}

Research has identified a range of factors in the child, the family and the social background which contribute to risk for the development of internalizing and externalizing problems, ${ }^{79}$ which also need to be targeted within a comprehensive package of preventive interventions for mental and physical health problems. Cost effective and simple interventions such as Pyramid Plus can form a very useful part of such packages. 


\section{Acknowledgments}

None.

\section{Conflicts of interest}

Author declares there are no conflicts of interest.

\section{Funding}

None.

\section{References}

1. Mc Culloch A, Wiggins D, Joshi H \& Sachdev D. Internalizing and Externalizing Children's Behaviour Problems in Britain and the US: relationships to family resources. Children and Society. 2000;14(5):368-383.

2. Copeland WE, Wolke, D, Angold A, et al. Adult psychiatric outcomes of bullying and being bullied by peers in childhood and adolescence. JAMA Psychiatry. 2013;70(4):419-426.

3. Niemela S, Brunstein Klomek A, Sillanmaki L, et al. Childhood bullying behaviors at age eight and substance use at age 18 among males: a nationwide prospective study. Addict Behav . 2011;36(3):256-260.

4. Biederman J, Hirshfeld Becker DR, Rosenbaum JF, et al. Further evidence of association between behavioral inhibition and social anxiety in children. Am J Psychiatry. 2001;158(10):1673-1679.

5. Copeland WE, Shanahan L, Costello EJ, et al. Childhood and adolescent psychiatric disorders as predictors of young adult disorders. Arch Gen Psychiatry. 2009;66(7):764-772.

6. Hiscock H, Bayer JK, Lycett k, et al. Preventing mental health problems in children: The Families in Mind population-based cluster randomised controlled trial. BMC Public Health . 2012;12:420.

7. Bongers IL, Koot HM, Van der End J, et al. The normative development of child and adolescent problem behavior. J Abnorm Psychol. 2003;112(2):179-192.

8. Broidy LM, Nagin DS, Tremblay RE, et al. Developmental trajectories of childhood disruptive behaviors and adolescent delinquency: a sixsite, cross-national study. Dev Psychol. 2003;39(2):222-245.

9. Degnan KA, Fox NA. Behavioral inhibition and anxiety disorders: Multiple levels of a resilience process. Dev Psychopathol. 2007;19(3):729-746.

10. Verona E, Sachs-Ericsson N, Joiner TE. uicide attempts associated with externalizing psychopathology in an epidemiological sample. Am $J$ Psychiatry. 2004;161(3):444-451.

11. Jones DJ, Lewis T, Litrownik A, et al. Linking childhood sexual abuse and early adolescent risk behavior: The intervening role of internalizing and externalizing problems. J Abnorm Child Psychol. 2013;41(1):139-150.

12. Degnan KA, Henderson HA, Fox NA, et al. Predicting social wariness in middle childhood: The Moderating Roles of Child Care History, Maternal Personality and Maternal Behavior. Soc Dev. 2008;17(3):471-487.

13. Rankin Williams L, Degnan KA, Perez Edgar KE, et al. Impact of behavioral inhibition and parenting style on internalizing and externalizing problems from early childhood through adolescence. $J$ Abnorm Child Psychol. 2009;37(8):1063-1075.

14. Zwierzynska K, Wolke D, Lereya T. Peer victimization in childhood and internalizing problems in adolescence : a prospective longitudinal study. J Abnorm Child Psychol . 2013;41(2):309-323.

15. Keiley MK, Bates JE, Dodge KA, et al. Effects of temperament on the development of externalizing and internalizing behaviors over 9 years. In: Columbus F (Ed.), Advances in psychology research, (Volume 6), Nova Science Publishers, New York, USA. 2012. P.256-288.
16. Huisman M, Araya R, Lawlor DA, et al. Cognitive ability, parental socioeconomic position and internalizing and externalizing problems in adolescence: Findings from two European cohort studies. Eur $J$ Epidemiol. 2010;25(8):569-580.

17. Bayer JK, Hiscock H, Ukoumunne OC, et al. Early childhood aetiology of mental health problems; A longitudinal population-based study. $J$ Child Psychol Psychiatry. 2008;49(11):1166-1174.

18. Erikson I, Cater A, Andershed AK, et al. What Protects Youths From Externalizing and Internalizing Problems? A Critical Review of Research Findings and Implications for Practice. Australian Journal of Guidance and Counselling. 2011;21(2):113-125.

19. Condly JS. Resilience in children. A review of literature with implications for education. Urban Education. 2006;41(3):211-236.

20. Crews SD, Bender H, Cook R, et al. Risk and protective factors of emotional and/or behavioural disorder in children and adolescents: A meta-analytic synthesis. Behavioural Disorders. 2007;32(2):64-77.

21. Harvey J, Delfabbro PH. Psychological resilience in disadvantaged youth: A critical overview. Australian Psychologist. 2004;39(1):3-13.

22. Masten AS. Resilience in developing systems: Progress and promise as fourth wave rises. Dev Psychopathol. 2007;19(3):921-930.

23. Rak FC, Patterson EL. Promoting resilience in at-risk children. Journal of Counselling \& Development . 2001;74:368-373.

24. Masten SA. Ordinary magic. Resilience processes in development. $A m$ Psychol. 2001;56(3):227-238.

25. Masten SA, Cutuli, JJ, Herbers, et al. Resilience in development. In: S.J. Lopez \& Snyder RS (Eds.), Oxford handbook of positive psychology ( $2^{\text {nd }}$ edn), Oxford University press, New York, USA. 2009. p. 117-131.

26. Kitano KM, Lewis BR. Resilience and coping: Implications for gifted children and youth at risk. Roeper Review. 2005;27(4):238-245.

27. Masten SA, Powell, LJ. A resilience framework for research policy and practice. In S.S. Luthar (Ed.), Resilience and vulnerability - adaption in the context of childhood adversities Cambridge: University Press. 2003.

28. Masten SA, O'Dougherty WM. Resilience over the lifespan: Developmental perspectives on resistance, recovery and transformation. 2010.

29. Rutter M. Resilience in the face of adversity. Protective factors and resistance to psychiatric disorder. Br J Psychiatry. 1985;147:598-611.

30. Luthar SS, Zelazo BL. Research on resilience-An integrative review. In: Luthar SS (Ed.), Resilience and Vulnerability-Adaption in the context of childhood adversities. Cambridge: University Press. 2003. p. 510-550.

31. Luthar SS, Zigler E. Vulnerability and competence: A review of research on resilience in childhood. Am J Orthopsychiatry. 1991;61(1):6-22.

32. O'Dougherty WM, Masten SA.Resilience processes in development. Fostering positive adaption in the context of adversity. In: Goldstein S \& Brooks BR (Eds.), Handbook of resilience in children. Kluwer Academic /Plenum Publishers, New York, USA. 2005. p.17-33.

33. Masten SA, Obradovic J. Disaster preparation and recovery: Lessons from research on resilience in human development. Ecology and Society. 2008;13(1):9.

34. Luthar SS. Resilience in development: A synthesis of research across five decades. In: Cicchetti D \& Cohen JD (Eds.), Developmental Psychopathology Volume 3: Risk disorder, and adaption (2nd edn), John Wiley \& Sons, Inc., New Jersey, USA. 2006. p.739-795.

35. Luthar SS, Sawyer AJ, Brown JP. Conceptual issues in studies of resilience: past, present and future research. Ann N Y Acad Sci. 2006;1094:105-115.

36. Karapetian AM, Grados, JJ. Enhancing resilience in children: A proactive approach. Professional Psychology: Research and Practice. 2005;36(3):238-245.

37. Herrenkohl IT, Sousa C, Tajima AE, et al. Intersection of child abuse and children's exposure to domestic violence. Trauma Violence Abuse. 2008;9(2):84-89. 
38. Keiley MK, Lofthouse N, Bates JE, et al. Differential Risks of Covarying and Pure Components in Mother and Teacher Reports of Externalizing and Internalizing Behavior Across Ages 5 to 14. J Abnorm Child Psychol. 2003;31(3):267-283.

39. Bryer F, Signorini J. Primary pre-service teachers' understanding of students' internalizing problems of mental health and wellbeing. Issues in Educational Research. 2011;221(3):233-258.

40. Asendorpf JB. Long-term development of shyness: Looking forward and looking backward. In KH Rubin \& RJ Coplan (Eds.), The development of shyness and social withdrawal, Guilford, New York, USA. 2010. p.157-175.

41. Coplan RJ, Prakash K, O’Neil K, et al. Do you "want" to play? Distinguishing between conflicted-shyness and social disinterest in early childhood. Dev Psychol. 2004;40(2):244-258.

42. Gazelle H, Ladd GW. Anxious solitude and peer exclusion: A diathesisstress model of internalizing trajectories in childhood. Child Dev. 2003;74(1):257-278.

43. Larson RW. The uses of loneliness in adolescence. In: Rotenberg KJ \& Hymel S (Eds.), Loneliness in childhood and adolescence. Cambridge University Press, New York, USA. 1999. p.244-262.

44. Oyserman D, Coon HM, Kemmelmeier M. Rethinking individualism and collectivism: Evaluation of theoretical assumptions and metaanalyses. Psychol Bull . 2002;128(1):3-72.

45. Weare K. Promoting mental health through schools. In: Aggleton P et al. (Eds.), Promoting health and well-being through schools. Routledge, London, UK. 2010. p.24-41.

46. Denham A, Hatfield S, Smethurst N, et al. The effect of social skills interventions in the primary school. Educational Psychology in Practice. 2006;22(1):33-51.

47. Frederickson N, Warren L, Turner J. 'Circle of Friends' - An exploration of impact over time. Educational Psychology in Practice. 2005;21(3):197-217.

48. Maddern L, Franey J, McLaughlin, et al. An evaluation of the impact of an inter-agency intervention programme to promote social skills in primary school children. Educational Psychology in Practice. 2004;20(2):135-155.

49. Stallard P, Simpson N, Anderson S, et al. The FRIENDS emotional health programme: Initial findings from a school-based project. Child and Adolescent Mental Health. 2007;12(1):32-37.

50. Durlak JA, Weissberg RP, Dymnicki AB, et al. The impact of enhancing students' social and emotional learning: A meta-analysis of school-based universal interventions. Child Dev. 2011;82(1):405-432.

51. King CA, Kirschenbaum DS. An experimental evaluation of a schoolbased program for children at risk: Wisconsin early intervention. Journal of Community Psychology. 1990;18(2):167-177.

52. Lowry-Webster HM, Barratt PM, Dadds MR. A universal prevention trial of anxiety and depressive symptomatology in childhood: Preliminary data from an Australian study. Behaviour Change. 2001;18:36-50.

53. Layard R. Happiness: Lessons for a new science. Penguin, London, UK. 2005.

54. Goleman D. Emotional intelligence. Bloomsbury, London, UK. 1996.

55. Denham SA, Blair KA, DeMulder E, et al. Preschool emotional competence: Pathway to social competence? Child Dev. 2003;74(1):238-256.

56. Eisenberg N, Fabes RA, Murphy B, et al. The relations of children's dispositional empathy-related responding to their emotionality, regulation, and social functioning. Developmental Psychology . 1996;32(2):195-209.

57. Mavroveli S, Sanchez-Ruiz MJ. Trait emotional intelligence influences on academic achievement and school behaviour. Br J Educ Psychol. 2011;81(pt1):112-134.
58. Petrides, KV, Pita R, et al. The location of trait emotional intelligence in personality factor space. Br J Educ Psychol. 2007;98(pt2):273-289.

59. Moroz KB, Jones KM, Kevin Jones M. The effects of positive peer reporting on children's social involvement. School Psychology Review. 2002;3(2):235-245.

60. Harris JR. Where is the child's environment? A group socialisation theory of development. Psychological Review. 1995;102(3):458-489.

61. Ladd G W, Herald-Brown S L, Reiser M. Does chronic classroom peer rejection predict the development of children's classroom participation during the grade school years? Child Dev. 2008;79(4):1001-1015.

62. Parker JG, Asher SR. Friendship and friendship quality in middle childhood: Links with peer acceptance and feelings of loneliness and social dissatisfaction. Developmental Psychology. 1993;29(4):611-621.

63. Mavroveli S, Petrides KV, Shove C, et al. Validation of the construct of trait emotional intelligence in children. Eur Child Adolesc Psychiatry. 2008;17:516-526.

64. Fabes RA, Hanish LD, Martin CL, et al. Young children's negative emotionality and social isolation: A latent growth curve analysis. Merrill-Palmer Quarterly. 2002;48(3):284-307.

65. Hymel S, Rubin KH, Rowden, et al. Children's peer relationships: Longitudinal prediction of internalizing and externalizing problems from middle to late childhood. Child Development. 1990;61:2004-2021.

66. Loades M, Mastroyannopolou K. Teachers' recognition of children's mental health problems. Child and Adolescent Mental Health. 2010;15(3):150-156.

67. Ohl M, Mitchell K, Cassidy T,et al. The pyramid club primary schoolbased intervention: Evaluating the impact on children's socio-emotional health. Child and Adolescent Mental Health. 2008;13(3):115-221.

68. Pyramid. Pyramid scheme club leader training manual. Pyramid, London, UK. 2007.

69. Goodman R. The extended version of the Strengths and Difficulties Questionnaire as a guide to child psychiatric caseness and consequent burden. J Child Psychol Psychiatry. 1999;40(5):791-799.

70. McKenna A, Cassidy T, Giles M. Prospective evaluation of the pyramid plus psychosocial intervention for shy withdrawn children: an assessment of efficacy in 7- to 8-year old school children in Northern Ireland. Child and Adolescent Mental Health. 2014;19(1):9-15.

71. Ohl M, Fox P, Mitchell K. Strengthening socio-emotional competencies in a school setting: Data from the Pyramid Project. Br J Educ Psychol. 2012;83(Pt 3):452-466.

72. ContinYou. About Pyramid. 2011.

73. Mavroveli S, Petrides KV, Sangareau Y, et al. Relating trait emotional intelligence to objective socioemotional outcomes in childhood. $\mathrm{Br} J$ Educ Psychol. 2009; 79(pt 2):259-272.

74. Webster Stratton C, Reid J, Hammond M. Social skills and problemsolving training for children with early-onset Conduct problems: Who benefits? J Child Psychol Psychiatry. 2001;42(7):943-952.

75. Goodman R. The Strengths and Difficulties Questionnaire: A research note. J Child Psychol Psychiatry. 1997;38(5): 581-586.

76. Bayer J, Hiscock H, Scalzo K, et al. Systematic review of preventive interventions for children's mental health: What would work in Australian contexts?. Aust N Z J Psychiatry.2009;43(8):695-710.

77. Hiscock H, Bayer JK, Price A, et al. Universal parenting programme to prevent early childhood behavioural problems: cluster randomised trial. British Medical Journal . 2008;336(7639):318-321.

78. Rose Krasnor L. The nature of social competence: A theoretical review. Social Development. 1997; 6(1):111-135.

79. TEIQue ( $1^{\text {st }}$ ed.), London Psychometric Laboratory, London, UK. 